\title{
EL LIDERAZGO POLÍTICO FEMENINO: LA DIFICULTAD DE UNA EXPLICACIÓN ${ }^{1}$
}

\author{
Paloma Román Marugán y Jaime Ferri Durá
}

Resumen: El incremento de mujeres en los puestos de liderazgo político en las democracias contemporáneas lleva a un replanteamiento de los diferentes enfoques y categorías de análisis que explican el fenómeno. En el caso del liderazgo femenino, se trata de un problema especialmente relevante, sobre todo en el espacio de la política, ya que su análisis específico es un terreno prácticamente ignoto. Este trabajo explóralos marcos teóricos del liderazgo y de género para ver la dificultad de los modelos utilizados en el análisis del fenómeno. No sólo explora la presencia y ausencia delos paradigmas tradicionales, sino también prueba con los modelos explicativos de otras culturas alternativas y del mundo del desarrollo. Palabras clave: Liderazgo, Mujeres, Sistemas Políticos, Género.

\section{Title in English: Female Political Leadership: Explanatory Difficulties}

Abstract: The increasing number of women in leadership roles in contemporary democracies demands reconsideration of the different analytical approaches and categories previously used to explain the development. The issue is especially relevant for political leadership as the analysis of female political leadership is at an embryonic stage. This paper aims to explore theoretical frameworks of leadership and gender, and to reveal both the lack and limitations of existing models for study of the phenomenon. The examination will include analysis of nonWestern leadership examples.

Key Words: Leadership, Women, Political Systems, Gender.

\section{Introducción}

La presencia de mujeres en el escenario político ha ido creciendo en los últimos años, en los regímenes democráticos con mayor pujanza e intensidad; e incluso se asiste a un incremento, más tímido, en los sistemas no democráticos. Bien sea, porque hay que dar su lugar a la mitad de la población de un país para respetar un índice de

\footnotetext{
${ }^{1}$ Fecha recepción: 30/08/2013

Fecha de aceptación: 07/11/2013

2 Profesores Titulares de Universidad, Departamento de Ciencia Política y de la Administración II, Universidad Complutense de Madrid, España; $\triangle$ romanmarugan@cps.ucm.es y ferri@cps.ucm.es.
} 
representación apropiado, o bien por mantener una retórica acompañada de mínimas acciones que sirvan para dar un toque de modernidad y de cumplimiento de estándares, que faciliten los marchamos democráticos de determinados sistemas políticos.

El caso es que este aumento de la presencia y una mayor visibilidad de las mujeres, en el ámbito político, sigue siendo escaso en términos cuantitativos en relación con la proporción de habitantes, por cada uno de los sexos; y además cualitativamente también resulta insuficiente porque la presencia de mujeres, en los puestos de poder, se circunscribe primordialmente en el campo de la política deliberativa, cuyo lugar por excelencia serían los parlamentos, mientras que en el terreno ejecutivo y decisional, aún son muy pocas. Tanto es así que, ese número reducidísimo de casos, nos lleva a dos afirmaciones básicas de este trabajo; una, que se trata siempre de excepciones, y dos, que por tanto se ha de trabajar con un número tan pequeño de casos ( $n$ pequeño) ${ }^{3}$, que resulta imposible trabajar con metodologías estadísticas, y casi resta únicamente acudir al método comparado, y por supuesto al inefable estudio de caso. Cuando se trata, como se sabe, de algo más de la mitad de la población mundial; si en la actualidad somos más de 7. 000 millones de personas ${ }^{4}$, lo que significa que son mujeres en torno a 3.600 millones y que de acuerdo con lo que se sostiene, cuando tienen que ser estudiadas en relación con el poder político, se ha de atender a casos particulares, o como mucho, ver su situación en unos u otros lugares. No se puede observar por ejemplo el número de mujeres al frente de gobiernos, porque es irrelevante; sólo se pueden citar algunas excepciones en una y otra parte.

De todos modos, la tesis fundamental de este trabajo se centra sobre todo en un problema teórico de difícil resolución. En síntesis, cuando nos enfrentamos a la explicación del liderazgo femenino, topamos con un inconveniente previo, de gran calado metodológico: la construcción de un marco teórico apropiado (Sabino 1996: 6790) que nos guíe adecuadamente en nuestra investigación. La mayoría de los marcos explicativos del liderazgo político en particular, y el liderazgo en general, se construyen

\footnotetext{
${ }^{3}$ El problema habitual de la política comparada: su dificultad por trabajar con un reducido número de casos, n pequeño. Véase Laiz y Román (2003: 5).

${ }^{4}$ De acuerdo con las estimaciones realizadas por los más reconocidos contadores, como http: //www. census. gov/main/www/popclock. html o http: //populationmatters. org/, visitadas el 20 de mayo de 2012.
} 
pensando en los modelos masculinos, como si se tratase de una trayectoria propia de una identificación de género. Por eso, esta cuestión también aparece como uno de los ingredientes fundamentales de toda esta problemática.

El hecho de que tradicionalmente se asocien los rasgos socialmente aceptados como propios de un líder a las cualidades habituales de la construcción social de la masculinidad, complican e inundan este concepto, de forma y manera, que empezamos sosteniendo la tesis de la imposibilidad de acudir a un diseño; no por supuesto femenino, sino neutral del liderazgo político, que resulte válido para explicar los pocos casos que la realidad nos brinda sobre este fenómeno.

Sin embargo, en términos concretos, es esencial que haya más mujeres en la política porque, cuando son pocas, se tiende a verlas como "mujeres" y les cuesta mucho que se reconozcan sus derechos y la valía de sus políticas. Y si tienen éxito, se ironiza con que parecen hombres. Si no tienen éxito, se achaca a que son mujeres y se las neutraliza políticamente, lo que no suele ocurrir con los hombres que se dedican a la política. Sumamente interesante en esta primera aproximación es el trabajo de D’Adamo, García Beaudoux, Ferrari y Slavinsky (2008) en el que plantean el peso de los estereotipos que penden sobre las mujeres candidatas a puestos políticos de gran relevancia política-concretamente abordan la cuestión de las mujeres candidatas a las elecciones presidenciales en Argentina-. Estos autores enfatizan el papel de los estereotipos y sus dimensiones tanto la descriptiva como la prescriptiva, valorando la especial exageración que se produce de este fenómeno en la política: las mujeres se enfrentan a muchos más problemas de imagen que los candidatos hombres, ya que aparecen como políticamente inexpertas, carentes de conocimiento, débiles de carácter y faltas de autonomía ${ }^{5}$.

\footnotetext{
${ }^{5}$ En este punto, se recuerda también el trabajo de Uriarte y Ruiz (1999: 207-232) donde analizando elites deliberativas - no ejecutivas- plantean también esa diferente óptica de apreciación sobre el trabajo de hombres y mujeres en política, cuando señalan que el liderazgo de las mujeres es más interactivo, participativo, menos agresivo y más integrador con respecto a sus subordinados.
} 


\section{El liderazgo político}

Este trabajo versa como ya se ha especificado claramente sobre mujeres líderes. Dando por supuesto que no hay que explicar el sustantivo, sí está claro que se precisa trabajar con el adjetivo. Por tanto, se debe comenzar clarificando qué es el liderazgo político $^{6}$. En primer lugar, hay que reconocer que se trata de uno de los conceptos fundamentales del análisis político, pero no tiene una definición rotunda e incontestada.

Salvando como lógico, los enfoques que pueda haber, los detalles y los matices con los que se quiera afrontar el fenómeno, el tratamiento que se va a utilizar en este trabajo es el más propio del análisis político empírico. Por tanto, se trata de identificar una relación; el liderazgo es un fenómeno relacional. Plantea pues la existencia de dos partes: el líder y los seguidores, absolutamente imprescindibles para que se produzca el fenómeno, más el añadido que sin duda aportan nuevas visiones sobre el liderazgo (Nye 2010), pero que tampoco ha sido ignorado por las anteriores, como Tucker (1976): la importancia del contexto.

\section{1. El líder}

Para comenzar con claridad, y siguiendo a Nye, ¿qué es un líder político?, o incluso mejor ¿qué hace un líder político? de acuerdo con su reflexión de que un líder no es tanto lo es que es, sino lo que hace. La respuesta es clara: el líder es aquel que ayuda a un grupo de personas a formular y a conseguir objetivos comunes.

\footnotetext{
${ }^{6}$ Un ejemplo de síntesis en el abordaje de este complejo concepto se puede encontrar también en Delgado Fernández (2004). En el mencionado trabajo el autor deja patente las dificultades del concepto, trabaja fundamentalmente con la idea del liderazgo como un proceso, y recomienda (2004: 18) un enfoque propio y ecléctico especial para este fenómeno en el ámbito político. De todos modos, las principales sugerencias de Delgado se basan en el trabajo seminal de Antonio Natera Peral (2001).
} 
Idea clara que encierra una enorme dificultad porque entraña conceptos complejos y de difícil o distinta interpretación. El liderazgo político es la función directiva por excelencia; siguiendo la perspectiva funcionalista que fue hegemónica hace tiempo en ciencias sociales, pero que aún es válida desde una visión de eclecticismo clásico de enfoques en ciencia política, si bien todas las actividades sociales tienen sus élites rectoras (Keller 1974). La función estratégica que cumplen las elites políticas se debe a su función primordial en el sostenimiento de la sociedad; por tanto, se trata de aquellas personas capaces de diagnosticar, diseñar y llevar a cabo un proyecto colectivo de una sociedad dada.

Las elites políticas llevan a cabo su función a través del control del poder político, entendido como el instrumento nuclear para hacer cumplir las decisiones que se toman para el arbitrio social y la puesta en práctica del proyecto diseñado. De ahí, la vinculación estrecha y, a veces, entendida como sinónima, entre liderazgo político y poder. Como en este trabajo no se entra en enfoques psicosociológicos, no se hará, pero es evidente que el atractivo del poder en sí mismo, como gran recurso, anima a determinadas personas a alcanzar puestos de decisión por sí mismo. Es ilustrativo recordar al sociólogo alemán Max Weber (2004: 156-157) cuando escribe:

\footnotetext{
Aunque el poder es el medio ineludible de la política o, más exactamente, precisamente porque lo es, y el ansia de poder es una de las fuerzas que la impulsan, no hay deformación más perniciosa de la fuerza política que el baladronear de poder como un advenedizo o complacerse vanidosamente en el sentimiento de poder puro en cuanto tal.
}

Por eso, no es de extrañar que se hable de los poderosos como aquellos que ejercen el liderazgo político, aunque también es verdad que no todos los poderosos son líderes políticos. Estos lo son en la medida en que el sistema les surte de privilegios y recursos para cumplir sus funciones, pero en términos relativos puede que no sean ni los únicos, ni los que tienen una mayor capacidad de influencia. Entre otras cosas, porque el 
liderazgo político, al menos de la cúspide es muy visible, y depende -en los sistemas democráticos- de los electores, con lo cual por mucho margen de maniobra que puedan tener en función el entramado institucional, o de la dinámica política del lugar, siempre hay un momento de la verdad: de rendición de cuentas, de la accountability, que les lleva a ser expuestos, criticados, recompensados o castigados; mientras que otros colectivos poderosos no están sujetos a una visibilidad, a una responsabilidad, y a una centralidad, tanto jurídico-política como mediática, que favorece la opacidad de sus decisiones.

Pero no sólo se han estipulado las funciones del liderazgo político, a través de su anclaje en la dirección política, expresión en la que podemos englobar la definición de Nye antes expuesta. Muchos autores han hecho hincapié en los datos propios de la personalidad del líder, aun dentro de la concepción del liderazgo como una relación.

Existe una de las tradiciones más rancias en la explicación del liderazgo, desde luego más anclada en el ámbito mitológico y literario más que politológico, como es el enfoque heroico. Se trata de aquella visión en que el líder es -fundamentalmente- un héroe épico, en general, de trayectoria militar y fraguado en numerosas batallas, caracterizado por llevar a cabo gestas cuyo resultado se premia más en alcanzar la gloria imperecedera y menos el bienestar de sus subordinados. Obra clásica de este enfoque sería el trabajo de Thomas Carlyle (1986).

Si abordamos el plano de la filosofía política, se puede viajar en el tiempo, y a modo de citas eruditas, empezar con la contribución de Platón, y su visión idealista y moral del liderazgo a través del concepto del rey filósofo. Y como no recordar, en este punto, la conocidísima obra de Nicolás Maquiavelo, Il Principe, donde el autor florentino aconseja como debe actuar un gobernante que quiere serlo y continuar en el empeño. Esta obra clásica, no deja de ser un modelo o hito por muchísimas razones: una por ser un espejo para Lorenzo de Médicis, a través de la figura del Rey Fernando de Aragón; y luego hay que recordar asimismo el interés que tiene la versión glosada, nada más y nada menos, que por el propio Napoleón Bonaparte como alumno aventajado; y 
sin olvidar una última razón, y muy humana, como que Maquiavelo la escribe buscando la gracia del señor que le facilite la salida de prisión.

No vamos a ir más allá en el recuerdo de retratos o perfiles de Príncipes que, por otro lado, fueron abundantes a lo largo de la historia; sobre todo porque corresponden a contextos no democráticos, donde el líder aparece en el vértice de la pirámide y emana órdenes y decisiones de arriba abajo, prácticamente, sin posibilidad de retroalimentación; salvo a través del magnicidio o tiranicidio, generalmente, vinculado a un recambio de la elite del poder.

En el ámbito de la sociología política lo que sí resulta imprescindible, en este retrato teórico acerca del liderazgo, es la aportación de Max Weber. Su contribución impregna con una importante variedad de conceptos el complejo fenómeno del liderazgo. Dentro de su gran apartado genérico de la Sociología de la dominación, aparecen los tipos ideales de legitimidad; donde ésta se convierte en un concepto capital para explicar la obediencia que arranca del poder, pero sin resistencia; luego aquí hay un componente clave: la otra cara de la moneda del poder. Todo líder que se precie sueña con una base confortable de legitimidad que le permita que sus decisiones sean acatadas, rápidamente, y al menor coste posible. La combinación que en los casos reales tiene la legitimidad tradicional, la legal-racional y la carismática, ha supuesto una ayuda inestimable en la observación y el análisis de los liderazgos políticos, no sólo desde el punto de vista personal, sino también relacional, que como se ha dicho ya varias veces, es el que nos resulta más operativo y con mayor capacidad explicativa para nuestros objetivos.

Aun así, también merece atención en esta breve construcción del perfil del líder, las cualidades y los defectos que un excelente observador como M. Weber nos proporciona. Seguimos insistiendo en que aunque se trate de cualidades personales resultan fundamentales para entender el liderazgo como una relación. Sin abordar todo su repertorio, el propio Weber en 1919 (2004) facilita en un texto relativamente menor como es su conferencia (luego pulida para su publicación): La política como vocación. Desde su dicotomía: se vive de la política o se vive para la política, planteando el 
problema de la remuneración y, en definitiva, el de la profesionalización que está hoy en día en el centro del debate. La transformación de la política como una empresa, y sus consecuencias, y la figura del político profesional y el funcionario de partido.

La parcialidad, la lucha y la pasión diferencian al político del funcionario (sine ira et studio). La disciplina de partido como característica de un tipo gregario de política, la de los partidos, protagonistas por otra parte de la escena política del Estado.

Las cualidades deseables en un político son pasión -al servicio de una causa-, sentido de la responsabilidad y mesura -guardando distancia-. Como defecto, y principal amenaza, Weber cita la vanidad.

Y como no recordar dos citas claves más: La diferenciación y sus consecuencias entre la ética de la convicción y la ética de la responsabilidad; y la importancia de la dignidad en la política, como no puede ser de otra manera, y en cualquier actividad que tenga la categoría de humana. Además del convincente final del texto, cuando proclama que aquel político, que tiene verdadera vocación, es quien a pesar de todas las dificultades de su misión, dice: sin embargo.

Otras aportaciones en el ámbito del enfoque en la personalidad del líder, que podrían ser tomadas en consideración, son el de macho alfa, que identifica al líder como aquel a quien sigue la manada, con rasgos estereotipados muy masculinos, con la espectacularidad de las proezas físicas, y en continuo litigio con los aspirantes a destronarle.

\section{2. Los seguidores}

El otro elemento necesario de la relación de liderazgo, como ya se apuntó, son los seguidores. Sin ellos no hay líder, por mucho empeño que tenga la potente vanidad humana. Tanto es así que, en este apartado, vamos a señalar dos conceptos fundamentales en la explicación del liderazgo, y uno de ellos, quizá sorprenda verlo en este epígrafe: el carisma; el otro, muy vinculado, el estado de necesidad. En el siguiente 
epígrafe, se trata un punto clave y muy relacionado con éste, la autonomía de los seguidores.

La naturaleza relacional del liderazgo conlleva necesariamente la existencia de dos partes: el líder y los seguidores. La fe, la confianza, o bien, la parsimonia o la dejadez ante la ausencia de alternativas, o cualquiera otra razón que arrastre en pos de un líder lo hemos dado en llamar carisma. Este concepto es tan famoso en ciencia política como poco manejable. Su eufonía y su halo simbólico ejercen un efecto de brillo que acaba oscureciendo su semántica. ¿Qué es el carisma? No es fácil ni de responder, y mucho menos de operacionalizar este concepto. Ya en 1976, la publicación del trabajo clásico de R. Tucker sobre la cuestión, ayuda a poner en claro algunas de las cuestiones que nos interesan: a) el carácter -asimismo- relacional del carisma, es decir que se trata de una percepción, y b) la aparición de un líder carismático depende el estado de necesidad (de la angustia) de una sociedad, comunidad, colectivo o grupo de seguidores. Es lo que este autor denomina el peso de la desgracia.

Basándonos en ellos, tomamos como referencia en este sentido, su definición de líder carismático: "es la persona en quien, por virtud de cualidades personales insólitas, parece encarnarse la promesa o esperanza de salvación” (Tucker 1976: 109). Luego aclara más que la percepción de dicho carisma puede ser situacional o puro, dependiendo ahí de un equilibrio entre la persona concreta y el momento de angustia colectiva.

\section{3. El contexto}

Desde este punto, resulta sencillo enlazar con el tercero de los elementos señalados al principio en la disección de los elementos del liderazgo: el contexto. Así, se acaba de perfilar un marco, muy especial, el vinculado a la percepción de carisma; por tanto se trata de un contexto de crisis. Pero aunque el conflicto y la tensión sean consustanciales a la política, se pueden identificar otros marcos, que también resultan útiles en la explicación del liderazgo: trátese de los contextos institucionales, sociales, 
económicos, partidistas, internacionales, etc. que influyen tanto en la definición como en las funciones del liderazgo.

Asimismo en este punto, hay que anotar cuestiones cruciales en el análisis político de hoy día, como es que los seguidores no son un "rebaño de ovejas obedientes" como pudiera parecer, como tópico, sino que existe una probada autonomía de los seguidores; y que su concurso es fundamental para el papel del líder, sobre todo en contextos democráticos, o en colectivos de ingreso libre como, por ejemplo, los partidos políticos ${ }^{7}$. Y otro dato más, de importancia, el poder del líder depende de los objetivos expresados (o consentidos) por los seguidores conforme a su cultura (Nye 2010: 43). Por tanto, la cultura política aparece como variable fundamental en el estudio y el análisis del liderazgo.

\section{4. Los estilos de liderazgo}

Pero además de estos rasgos de la personalidad, y siguiendo en línea con la propuesta de Nye, de que el liderazgo no es lo que es sino lo que se hace, ampliemos con los nuevos conceptos que se aportan en torno al liderazgo.

Hablar de estilos de liderazgo, supone escribir sobre los rasgos de los modelos complejos en los que se puede combinar esa relación que supone el liderazgo político. En los estilos de liderazgo, pues, encontramos al líder y sus capacidades y sus aprendizajes, las necesidades y pautas culturales de los seguidores, y la relación que se establece a través de las pautas de interacción de unos y otros. De esa manera, siguiendo a Nye, habrá que citar la diferencia entre Hard y Soft power, y su combinación perfecta, llamada Smart power.

Todo ello para diferenciar el liderazgo transformativo y el liderazgo transaccional. El primero es aquel modelo de liderazgo que responsabiliza y exalta a los propios seguidores, explorando el conflicto y la crisis para conocerla y

\footnotetext{
${ }^{7}$ Véase Panebianco (1990).
} 
transformarla. Este tipo de liderazgo induce a los seguidores a trascender los intereses particulares; el carisma es un aspecto más (Nye 2010: 73).

El liderazgo transaccional apela a los intereses particulares de lo seguidores, dependiendo más del castigo y la recompensa. El mismo líder debe ser capaz de crear incentivos y definir las reglas de su obtención (Nye 2010. 74).

Los dos estilos se han de combinar con recursos Hard y Soft, dependiendo del contexto (el tercer vértice de la relación). Sin poder agotar en este espacio, los rasgos característicos de las dos formas de poder, hay que recordar que los recursos propios del Soft power son: habilidad comunicativa, carisma, inteligencia emotiva, persuasión, capacidad de visión. En el perfil del modelo Hard, sin embargo hay que hablar de habilidad organizativa, y habilidad política, entendida como la capacidad de acumular capital político para negociar continuamente (Nye 2010: 95). La combinación adecuada de los dos tipos de recursos, configura el llamado Smart Power, caracterizado por la concurrencia de inteligencia contextual: "el liderazgo es un arte interactivo en el que el sujeto 'baila' con el contexto, el problema, las facciones y el objetivo" (Nye 2010: 102), la comprensión del contexto cultural, el manejo adecuado de las crisis y la noción de urgencia, y el control del flujo de información.

De modo panorámico, también cumple añadir que, las importantes transformaciones sociales de los últimos años, como la revolución tecnológica, la extensión de la democratización, no sólo política sino social, la globalización que nos lleva a no encontrar fronteras, en el sentido de poder conocer en cualquier momento y lugar lo que ocurre en la otra punta del mundo, y por tanto a conocer y a reconocer otras culturas, están modelando un mundo menos jerárquico, más reticular; esa circunstancia va imponiendo un modelo de liderazgo menos vertical y mucho más horizontal; se busca más un coordinador que un director dando órdenes. Se precisa más una persona comunicativa, participativa e integradora, que un jefe con bastón y silbato que ahora resulta menos eficaz. 
A este nuevo estilo de liderazgo, que tiene unos rasgos más amables y contemporizadores, se le ha dado en llamar incluso estilo femenino de liderazgo, frente al modelo masculino ligado a la verticalidad y a la orden. Esta cuestión no deja de ser un estereotipo más. Es cierto que las condiciones de vida de las mujeres, en casi todas las sociedades incluidas las occidentales, presentan unas barreras de oportunidad frente a los hombres, que impiden correr con ellos en igualdad de condiciones. Pero no por eso se debe caer en el estereotipo de la amabilidad de la mujer frente al modelo masculino, próximo al estilo heroico o de machos alfa, antes mencionados ${ }^{8}$.

Esta desigualdad en la estructura de oportunidades en las carreras políticas de las mujeres, junto a las pautas culturales que las complementan, ayudando a ese menoscabo, ha dado origen a una expresión ya famosa, la de techo de cristal para denominar esa frontera invisible pero real que impide a las mujeres subir más arriba, incluso en las sociedades democráticas donde teóricamente los derechos y las obligaciones de ambos sexos son las mismas. Esa expresión está cambiando en los últimos tiempos, quizá por otra más adecuada a los nuevos tiempos, la de laberinto de cristal (Barberá, Ramos y Candela, 2011), poniendo de manifiesto la posibilidad de perderse en los caminos intrincados de un lugar metafórico que tiene una entrada pero una complicadísima salida.

\section{Los liderazgos femeninos}

En el apartado anterior, se ha intentado hacer un bosquejo breve y ecléctico acerca de la comprensión teórica con que trabajamos en la ciencia política sobre el fenómeno del liderazgo.

\footnotetext{
${ }^{8}$ Desde la Psicología social refiriéndose a contextos organizacionales, en general, no políticos, se han explorado estas cuestiones, con resultados no definitivos, pero interesantes, véase: Cuadrado (2004: 270275), Cuadrado, Molero y Navas (2003: 115-119), y de Ayestarán (2003: 315-319) sobre todo la pregunta que lanza a Isabel Cuadrado al final de su artículo.
} 
Como se sostenía en la introducción de este trabajo, el escaso número de casos de liderazgo femenino impide tratar este fenómeno de forma categorial, y por tanto, la mayor parte de las veces, hay que reducirlo a excepciones. Esta singularidad produce dos consecuencias metodológicas: una, que la mayoría de los pocos casos son vistos a la luz de los modelos fundamentalmente masculinos, y por tanto mimetizan los casos dados en función de esos rasgos; y dos, no hay explicación para aquellos casos que no siguen esas pautas.

De todos modos, antes que nada, cumple hacer una distinción interesante en nuestra disquisición, que también fue apuntada en la introducción: si bien la presencia femenina en el ámbito político es creciente tanto en los sistemas democráticos como en los no democráticos, es conveniente matizar lo siguiente: hay un diferencia considerable en todos los países del mundo entre la presencia de mujeres en los espacios deliberativos (parlamentos, asambleas, consejos, comisiones, etc. ...), y la existencia de puestos de carácter ejecutivo desempeñados por mujeres; este sigue siendo un terreno casi exclusivo de los hombres.

Esta situación supone dos circunstancias (que a la vez funcionan como causa y consecuencia): la mayor relevancia social y de visibilidad tanto por prestigio, privilegio como por importancia en la dirección política de los Estados de la que gozan los puestos ejecutivos; condiciones a la que se une, una más, y no menos importante: su escasez, entendida lógicamente como ingrediente de valor.

Los espacios de carácter deliberativo sí están constituyendo el escenario al que se suben más mujeres; tampoco se puede hablar ni de un gran número, ni de una gran velocidad $^{9}$, pero es un indicador que está sirviendo para observar, medir e interpretar el avance político de las mujeres ${ }^{10}$.

\footnotetext{
${ }^{9}$ Veáse www.ipu.org/wmn-e/world.htm. Corresponde a la página web de InterparlamentaryUnion, en su apartado Women in Parliaments.

${ }^{10}$ Conviene señalar en este punto un interesante estudio sobre el caso español elaborado por Tania Verge (2006) sobre las estrategias desarrolladas por los partidos políticos para incrementar la presencia de la mujer en las instituciones. Sus conclusiones hablan de avance (en el terreno legislativo, no tanto en el
} 
Además, en este punto, hay que recordar, el impulso añadido que supone para aquellos datos, la aplicación de los resultados del tercero de los Objetivos de Desarrollo del Milenio (ODM), aprobados en la Cumbre de las Naciones Unidas del mismo nombre celebrada en 2000. Dicho objetivo reza: "Promover la igualdad de género y el empoderamiento de las mujeres" 11 , entre los indicadores ${ }^{12}$ de medición y seguimiento del objetivo está la proporción de escaños ocupados por mujeres en el Parlamento nacional. En este punto y a la luz de los datos, se puede observar un crecimiento sustantivo en la mayoría de los casos debido a la implementación de medidas de discriminación positiva como las $\operatorname{cuotas}^{13}$, y de ahí podemos encontrar un número importante de datos que recogen este ascenso, tanto en la página web ya mencionada de la Interparlamentary Union, como en los distintos informes anuales de cumplimiento de los $\mathrm{ODM}^{14}$.

De manera muy resumida - consultar cuadro $\mathrm{n}^{\mathbf{0}} 1-$, nos encontramos con un ascenso pero no demasiado significativo con respecto a las metas previstas en torno a lograr la paridad. También se comprueba que la presencia creciente, es a la vez muy

ejecutivo), y es digna de mención su alusión al Círculo virtuoso que se ha dado en España por la competición entre los dos grandes partidos en la carrera de quien presenta más mujeres. El estudio abarca hasta el año 2004, por lo que no puede entrar en el avance más claro en los puestos ejecutivos (ministerios) que se va a operar con el presidente Rodríguez Zapatero, consiguiéndose gobiernos paritarios. Situación que acabará en 2011 con el triunfo del PP.

${ }^{11}$ El empoderamiento consiste en un proceso de otorgamiento de poderes a las mujeres para que se hagan más presentes, y por tanto visibles, allí donde su existencia y su importancia no están a la altura de los niveles de toma de decisiones que sí les afectan. El empoderamiento enfatiza la visibilidad y un mayor protagonismo activo de las propias vidas de las mujeres (Román Marugán y Ferri Durá, 2008: 79). Hay que recordar en este punto que la estrategia del empoderamiento surge entre las mujeres del Sur y tiene su antecedente, más remoto, en la relación entre el feminismo y la educación popular en América Latina (Hainard y Verschuur 2002: 197 y ss; y Batliwala 1997: 187-211).

${ }^{12}$ Los demás indicadores vinculados al tercer objetivo son los siguientes: Relación entre niños y niñas en la educación primaria, secundaria y superior; relación entre las tasas de alfabetización de las mujeres y los hombres de edades comprendidas entre los 15 y 24 años; y proporción de mujeres en empleos asalariados en el sector no agrícola.

${ }^{13}$ Véase entre muchos los magníficos trabajos de Ojeda Rivera (2006) y de Llanos y Simple (2008).

${ }^{14}$ Véase Naciones Unidas 2011: 27, 2012: 26 y 2013: 22. 


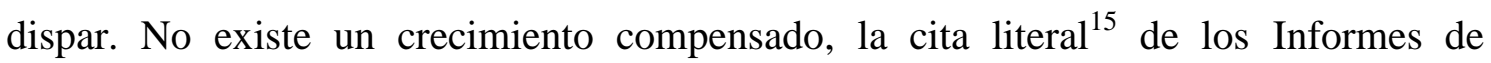
Naciones Unidas, sobre el cumplimiento de los ODM, es muy clara:

\begin{abstract}
A principios de 2011, las mujeres representaban el $30 \%$ o más de los integrantes parlamentarios (en parlamentos unicamerales o en la cámara baja) en 25 países, lo cual incluye los siete países donde ocupaban el $40 \%$ o más de los escaños. Algunos países han logrado altos niveles de representación de las mujeres en ambas cámaras: Rwanda (56, 3\%), Suecia (45, 0\%), Sudáfrica $(44,5 \%)$ y Cuba $(43,2 \%)$. Por el contrario, 48 países tienen menos de un $10 \%$ de mujeres en la cámara baja o en parlamentos unicamerales. Nueve países (Arabia Saudita, Belice, los Estados Federados de Micronesia, las Islas Salomón, Nauru, Omán, Palau, Qatar y Tuvalu) no tienen ni una mujer parlamentaria.
\end{abstract}

De esta manera, se puede comprobar, aun a vista de pájaro, la situación del avance -numérico- de las mujeres en los puestos políticos deliberativos. No podemos entrar por razón de espacio, ni de capacidad en una valoración cualitativa de esa presencia; pero habida cuenta de los siglos de invisibilidad, no se puede negar un avance sustantivo de la participación de la mujer en el ámbito político, y su consecuencia más relevante: la posibilidad real de que sus puntos de vista, sus reivindicaciones y sus propuestas de solución a los problemas de la sociedad, sean tenidos en cuenta. Pues con más mujeres en la política, es más fácil apreciar que los problemas de las mujeres no son sólo de ellas -la violencia de género, por ejemplo-; son de todos.

Porque la diferencia fundamental en política no es el género; es la exclusión. En el caso aquí analizado, la exclusión (¿sistemática?) de las mujeres de los puestos y espacios de poder/responsabilidad política. Y es obvio que a la hora de buscar soluciones, por ejemplo, frente a la violencia contra las mujeres, es más difícil acertar si no se hace desde la perspectiva de la mujer, desde la perspectiva de género, tanto en los parlamentos, como en las policías, la justicia o el sistema de asistencia. Y de la misma manera, una sola mujer en un tribunal, aunque esté en minoría, sin duda influirá en la perspectiva de sus compañeros varones por su capacidad para aportar la visión desde esa importante parte, al menos cuantitativamente, de la sociedad.

\footnotetext{
${ }^{15}$ Véase Naciones Unidas 2011: 22.
} 
Pero, volviendo sobre el argumento, queda por comentar la otra dimensión: la presencia de la mujer en los puestos políticos ejecutivos. Como ya se ha especificado, la cuestión cambia radicalmente. Para dar el paso a este fenómeno, hay que recordar la siguiente cita correspondiente al Informe de los ODM del año 2011 (2012: 22). En este párrafo se pone de manifiesto que aunque sí se comprueba un avance en la presencia en los órganos de representación y deliberación (e incluso un tímido avance en sus presidencias), el gran abismo se sitúa en los principales puestos de dirección política (Jefaturas del Estado y Jefaturas de Gobierno).

Los sistemas de cupos y las medidas tomadas por los partidos políticos siguen siendo claves para lograr mejoras representativas. Los cupos determinados por ley o establecidos por los propios partidos políticos se han puesto en práctica para el $67 \%$ de las 43 cámaras bajas que cuentan con un $30 \%$ o más de integrantes mujeres. En cuanto a puestos de liderazgo, por primera vez dos parlamentos eligieron mujeres para presidirlos: el de Mozambique y el de la República Unida de Tanzania. En todo el mundo, las mujeres ocupan actualmente solo el 13, 4\% de las presidencias parlamentarias. En enero de 2011, solo 10 países tenían a mujeres como jefas de Estado, y en 13 países había mujeres como jefas de gobierno.

Así es, y aún se pueden dar más datos que ayudan a proporcionar una idea más acorde con la dimensión del problema, Nye ( 2010: 60-61) cita un estudio que muestra que sólo el 5\% de los puestos directivos de las grandes empresas son desempeñados por mujeres; que en las Asambleas legislativas electas, el número oscila entre el $45 \%$ de Suecia y el $16 \%$ en Estados Unidos. Pero lo más significativo son los datos que aporta sobre el siglo XX, en el que se han contabilizado 1941 Jefes de Estado en países independientes; de ellos sólo 27 han sido mujeres; la mitad de las cuales han llegado al poder como viudas e hijas de un gobernante masculino, en otras palabras, las mujeres que accedieron al poder con sus propios medios han sido menos del $1 \%$ de los Jefes de Estado del siglo pasado: 
Gráfica 1.

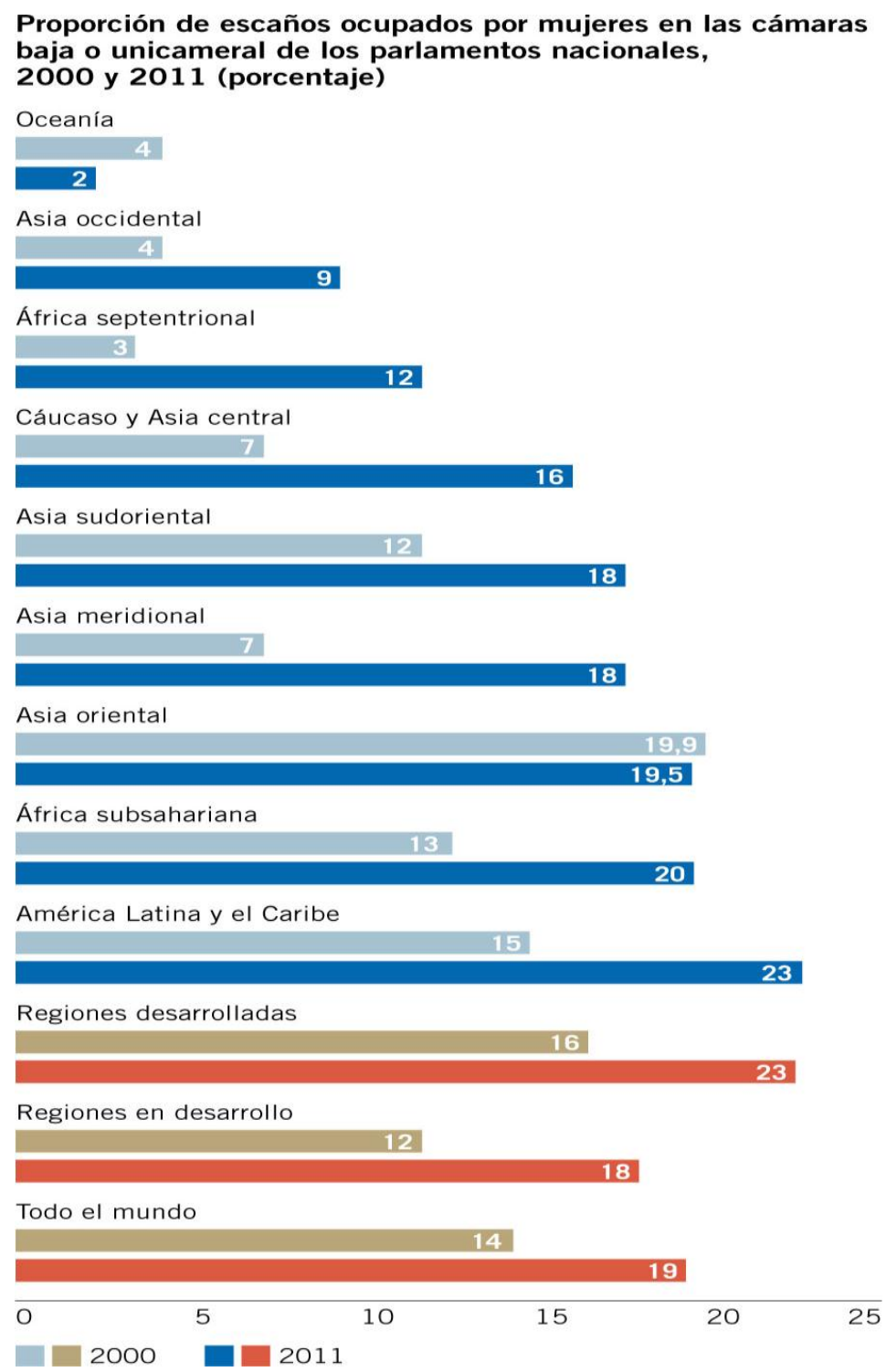

Fuente: Informe 2011 Objetivos de Desarrollo del Milenio, Naciones Unidas

La cita anterior nos sirve para plantear cuestiones claves de los interrogantes de este trabajo. $\mathrm{Y}$ esa vinculación explicativa entre los liderazgos en general y los masculinos. Sólo un $1 \%$ de los líderes políticos máximos de los Estados independientes del mundo durante el siglo XX han sido mujeres que han alcanzado el poder como la 
mayoría de los hombres líderes, siguiendo una carrera política exitosa. El resto de los pocos casos de mujeres lideresas, lo han sido como parte de una familia, de un carisma, o de una carrera política exitosa prestada. No significa en absoluto que dichas mujeres careciesen de talento o habilidad $^{16}$, pero seguro que de no estar rodeadas de esas circunstancias familiares y sociales, no habrían ocupado sus cargos.

Estos hechos ponen de manifiesto, cuestiones relevantes en el estudio del liderazgo, concretamente con la cuestión del carisma. Se trata del fenómeno de la "rutinización” y la "despersonalización” del carisma. Tanto Max Weber, como Robert Tucker, en su intento de hacer más operativo el concepto de carisma sostienen que la relación carismática puede transformarse desde una relación personal y extraordinaria a otra; por ejemplo, de un líder a otro, de acuerdo con las reglas de sucesión establecidas (designación, cooptación, elección, etc. ...). Tucker (1976: 123) escribe: en el proceso de "despersonalización", el carisma evoluciona pasando a ser un carisma hereditario o "familiar".

Esta observación certera sobre el carisma, nos lleva a analizar el fenómeno antedicho, donde son mujeres líderes porque en ellas continua el carisma de su padre, o esposo, o incluso madre. Ejemplos bien conocidos: Indira Gandhi, era la hija de Nehru, Benazir Butto, fue la hija de Zulfikar Alí Butto, Aung San Suu Kyi es hija del héroe nacional birmano Aung San. Chandrika Kumaratunga, presidenta que fue de Sri Lanka, es la hija de la legendaria Sirimavo Bandaranaike, la primera mujer asiática en gobernar un país independiente ${ }^{17}$. En el panorama actual está Marine Le Pen, Hillary Clinton, o

\footnotetext{
${ }^{16}$ Al contrario, si seguimos a García-Retamero y a López-Zafra (2008: 12), en las organizaciones empresas por lo general- que estudian se observa que: a pesar de quelas mujeres tengan menos oportunidades que los hombres a la hora de obtener un cargo donde deban desempeñar el rol de líder, éstas presentan ciertas característicasque las hacen líderes más eficaces en las organizaciones contemporáneas. Concretamente, las líderes mujeres son menos jerárquicasy más cooperativas y con frecuencia incrementan la autoconfianza de susseguidores en mayor medida que los líderes hombres. Es más, las mujeres muestran un estilo más transformacional de liderazgo que los hombres. Los líderes quemuestran este estilo de liderazgo ganan la confianza de sus seguidores, estableciéndosecomo modelos en el grupo. Todo lo que agudizaría la tesis que aquí se defiende, haciéndola aún más paradójica.
}

\footnotetext{
${ }^{17}$ Para afrontar un breve recuerdo a estas mujeres pioneras en el desempeño de tareas políticas ejecutivas de máximo nivel, se pueden consultar las obras de Genovese (1997) y de Segura Graiño (1998).
} 
Cristina Fernández. Entre los pocos casos que podemos encontrar rebuscando en el primer modelo, está Angela Merkel, Dilma Roussef o Ellen Johnson-Sirleaf, y en el ya pasado mediato, Golda Meir; si bien entre estas también debiera tenerse en cuenta que algunas fueron nominadas por sus antecesores, varones, por lo que puede decirse que, en parte, "han heredado" el puesto.

Gráfica 2. Jefes de Estado de países independientes en el siglo XX

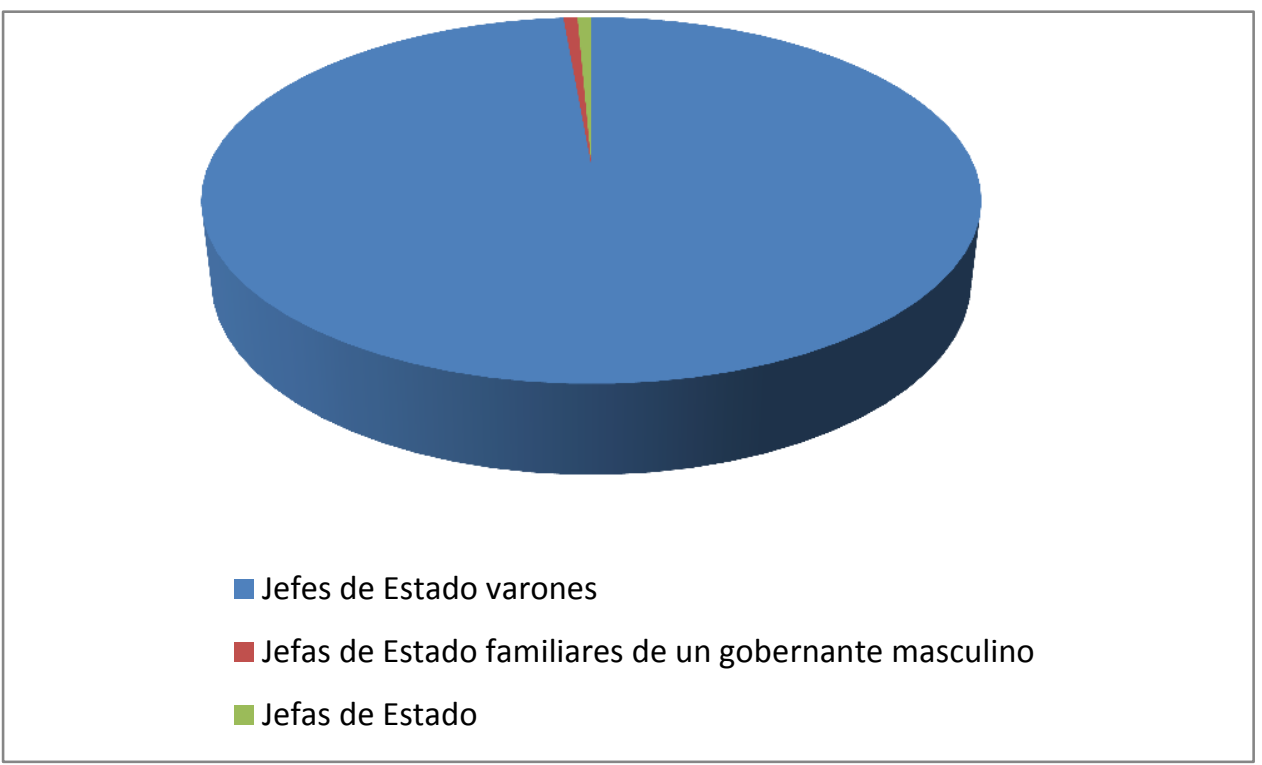

Fuente: elaboración propia a partir de los datos suministrados por A. Ludwig (2002: 22-23)

Hoy día, se puede esgrimir el ejemplo latinoamericano para poner de manifiesto el predominio de la mujer en política, pero se trata de un espejismo que se desvela a poco que se investigue. Hasta 1999, la nicaragüense Violeta Chamarro era la única mujer elegida para ocupar la presidencia de un país de Latinoamérica. Argentina, Bolivia habían tenido presidentas, pero ninguna llegó a ocupar ese cargo como resultado de un proceso electoral. Desde entonces se ha visto una ola de mandatarias aparentemente cada vez más poderosas: Mireya Moscoso de Panamá, Michelle Bachelet de Chile, Cristina Fernández de Kirchner de Argentina, Laura Chinchilla de Costa Rica 
y Dilma Rousseff de Brasil ${ }^{18}$. En pocos años, una región conocida por su secular machismo parece que se ha convertido en la vanguardia de la igualdad entre sexos, por lo menos en la cúspide del poder político. Pero sería un error confundir la disposición del electorado a votar por una mujer con una verdadera y profunda expansión de la libertad y la igualdad de género. Pues la igualdad implica mucho más que sólo conseguir ellas los puestos de mandatarias. También tiene que tomarse en cuenta a qué tipo de mujeres acepta el pueblo como líderes, cómo llegan al poder (obsérvese que todas las citadas fueron designadas, más o menos, directamente por sus predecesores, hombres), qué tipo de comportamiento se espera de ellas en su cargo y cuáles políticas de gobierno pueden aplicar.

Y el otro aditamento sobre el carisma que merece la pena remarcar, es que como es una percepción por parte de los seguidores de que determinada persona es el mejor líder posible, e incidiendo en la importancia del contexto - y el estado de necesidad-, es lógico que esa percepción se amolde de manera adecuada a los patrones culturales de esa sociedad. Si por regla general, las sociedades responden a pautas patriarcales, donde el hombre es el protagonista por excelencia, es difícil que pueda surgir una lideresa carismática, sus posibilidades casi estadísticas son prácticamente inexistentes.

\section{Conclusiones}

De manera sintética, se van a reseñar los principales argumentos esgrimidos a la largo de esta reflexión:

1. La función de liderazgo político es fundamental para el sostenimiento de las sociedades. Dentro de la etiqueta de liderazgo político, se puede distinguir entre liderazgo político en ámbitos deliberativos (Asambleas, Parlamentos, Consejos, Comisiones, etc.), y liderazgo político en ámbitos ejecutivos, es decir de dirección política.

\footnotetext{
${ }^{18}$ Véase, ForeignAffairs Latinoamérica (2011), monográfico dedicado a "Mujeres y política pública".
} 
2. Las mujeres suponen la mitad de la población mundial en términos cuantitativos y sin embargo, su participación política en los distintos niveles de liderazgo es insuficiente en proporción a su presencia. Resulta ser sin duda alguna, la mayor de las minorías del planeta.

3. En los últimos tiempos, la presencia de las mujeres en los puestos de poder, ha mejorado gracias en primer lugar al reconocimiento del problema y por tanto a las acciones paliativas acometidas: programas activos, y la utilización de instrumentos de discriminación positiva, concretándose sobre todo en los puestos de liderazgo en el ámbito deliberativo, lo que resulta ser un logro al poder incorporar el punto de vista femenino para visibilizar problemas y soluciones. Véase el cuadro $\mathrm{n}^{\circ} 1$.

4. En los puestos de poder de ámbito ejecutivo queda muchísimo más por hacer. El retraso es proverbial, y las posibilidades de crecimiento de la presencia de la mujeres en este escenario tiene que ver también con la propia transformación social en cuanto a las relaciones de género, la formación, la conciliación y la igualdad de oportunidades para dedicarse a la función política. Por las aportaciones de los estudiosos en el tema, y en este ámbito, se pueden encontrar dos tipos de mujeres lideresas, por ejemplo a lo largo del siglo XX: a) aquellas que heredan el carisma/puesto de un familiar y b) las capaces de generar y triunfar por sus propios medios. Contabilizándose la suma de ambos casos en una cifra minúscula, todavía las primeras constituyen más casos que las segundas.

5. La situación actual mezcla de progreso, pero también de retórica, lleva incluso a casos perversos, en de cara a la imagen o los cálculos electorales, se precisa un liderazgo femenino, que se fabrica sin demasiado fuste, contribuyendo negativamente a la verdadera presencia femenina en los puestos de poder. Como ejemplo de estas palabras, sirva el caso de Sarah Palin, excelentemente retratado en la película Game Change (2012) dirigida por Jay Roach.

6. La tesis defendida en este trabajo se basa en todos los puntos anteriores entendidos como preliminares: es difícil buscar una explicación teórica del liderazgo político femenino debido a que, ni siquiera existe una teoría sobre el 
liderazgo político neutral, sino que los enfoques y todo el material analítico se basa en los casos mayoritarios que son masculinos.

7. Esta última afirmación se comprueba con facilidad al descender algunos detalles, que aquí, sin más profundización, sirvan tan sólo como ejemplo. La proliferación de enfoques explicativos como el heroico, o el del macho alfa, o el propio concepto de carisma, tan utilizado como complejo, pero que prácticamente descarta a las mujeres en el establecimiento de perfiles, porque como es lógico depende de los patrones de cultura política de cada sociedad; todo ello sin entrar en otras variables sustantivas del carisma que también se ven afectadas en este sentido.

8. En los últimos estudios sobre estilos de liderazgo, tal como la distinción por ejemplo entre liderazgo transformativo y liderazgo transaccional, aparece de forma más nítida un modelo que se tilda incluso de femenino como sería el transformativo, caracterizado por utilizar recursos Soft, frente a la contundencia de los Hard. Pero esta identificación no deja de ser un estereotipo más. Es vincular un modo de hacer las cosas a una serie de características asignadas culturalmente a las mujeres a través de las relaciones de género, por lo que tampoco se puede mostrar satisfacción por ello.

9. En definitiva, lo que queda sobre la mesa, es la necesidad de seguir buscando mejores patrones explicativos para un fenómeno de crecimiento lento pero imparable, que tiene que ver con las mejoras en los sistemas de representación y de gobernación democráticas. De alguna manera se está instalado en un círculo vicioso porque no hay casos, y por eso no hay fenómenos de estudio en un número realmente significativo para que deje de ser una excepción. 


\section{Referencias bibliográficas}

Ayestarán, Sabino. 2003. “¿Dirigen las mujeres igual que los hombres?”. Revista de Psicología Social, 18 (3), 315-319.

Batliwala, Srilatha. 1997. "El significado del empoderamiento de las mujeres. Nuevos conceptos desde la acción". Poder y empoderamiento de las mujeres. Coord. Magdalena de León, Bogotá: TM Editores.

Barberá Heredia, Esther, Amparo Ramos López y Carlos Candela Agulló. 2011. "Laberinto de cristal en el liderazgo de las mujeres", Psicothema, vol. 23, n" 2, 173-179.

Carlyle, Tomás 1986: Los héroes. El culto de los héroes y lo heroico en la historia. México: Porrúa.

Cuadrado Isabel, Molero Fernando y Marisol Navas. 2003. "El liderazgo de hombres y mujeres: diferencias en estilos de liderazgo, relaciones entre estilos y predictores de variables de resultado organizacional. Acción Psicológica, vol. 2, $\mathrm{n}^{\mathrm{o}}$ 2: 115119.

Cuadrado, Isabel. 2004. "Valores y rasgos estereotípicos de género de mujeres líderes". Psicothema, vol. 16, $\mathrm{n}^{\mathrm{o}}$ 2, 270-275.

D’Adamo, Orlando, Virginia García-Beaudoux, Gladys Ferrari y Gabril Slavinsky, Gabril. 2008. "Mujeres candidatas: percepción pública del liderazgo femenino". Revista de Psicología Social, 23, 1, 91-104.

Delgado Fernández, Santiago. 2004: "Sobre el concepto y estudio del liderazgo político. Una propuesta de síntesis". Psicología Política 29, 7-29.

Foreign Affairs Latinoamérica (2011), V. 11, n 3, monográfico dedicado a "Mujeres y política pública".

García-Retamero, Rocío y Esther López-Zafra. 2008. "Atribuciones causales sobre éxito y fracaso y percepción del liderazgo femenino". Estudios de Psicología, 29, 3: 273-287.

Genovese, Michael A. 1997. Mujeres líderes en política: modelos y prospectiva. Madrid: Narcea.

Hainard, François y Christine Verschuur. 2002. Empoderamiento de las mujeres en las crisis urbanas. Madrid: IEPALA.

Keller, Suzanne. 1974. Más allá de la clase dirigente. Madrid: Tecnos. 
Laiz, Consuelo y Paloma Román. 2003: Política Comparada. Madrid: McGraw-Hill.

Llanos, Beatriz y Kristen Simple. 2008. 30 años de democracia: ¿en la cresta de la ola? Participación política de la mujer en América Latina. Perú: IDEA.

Ludwig, A. 2002. King of the Mountains: The Nature of Political Leadership. Lexington: University of Kentucky.

Naciones Unidas. 2011, 2012 y 2013. Objetivos de Desarrollo del Milenio, Informe 2010, Informe 2011, Informe 2013, Nueva York.

Natera, Antonio. 2001. El liderazgo político en la sociedad democrática. . Madrid: CEPC.

Nye jr., Joseph, S. 2010. Leadership e Potere: Hard, Soft, Smart Power. Bari: Laterza.

Ojeda Rivera, Rosa Icela. 2006. "Las cuotas de género para el empoderamiento de las mujeres" en El Cotidiano [en linea] 2006, 21 (julio-agosto). http: //redalyc. org/articulo. oa?id=32513805. ISSN 0186-1840 [26 de noviembre de 2013].

Panebianco, Angelo. 1990. Modelos de partido. Madrid: Alianza.

Román Marugán, Paloma y Jaime Ferri Durá . 2008. "La participación política y el empoderamiento social de las mujeres". Pobreza, Mujeres y Medio Ambiente. Coord. Paloma Román Marugan. Madrid: Fundación IPADE-UCM.

Sabino, Carlos. 1996: El proceso de investigación. Medellín: Cometa de Papel.

Segura Graíño, Cristina. 1998. Diccionario de Mujeres Célebres. Madrid: EspasaCalpe.

Robert Tucker 1976: "La teoría del liderismo carismático". Filósofos y Estadistas. Ed. D. A. Rustow. México: FCE.

Uriarte, Edurne y Cristina Ruiz. 1999. "Mujeres y hombres en las élites políticas españolas: ¿diferencias y similitudes?”. REIS, 88, 207-232.

Verge, Tania. 2006. "Mujer y partidos políticos en España: las estrategias de los partidos y su impacto institucional. 1978-2004". REIS, 115, 165-196.

Weber, Max. 2004. El político y el científico. Madrid: Alianza. 